\title{
A New Video Editing Technology in Practical Teaching of Animation
}

\author{
http://dx.doi.org/10.3991/ijet.v11i09.6125 \\ Yufeng Shen \\ University of Science and Technology Liaoning, Anshan, China
}

\begin{abstract}
The animation practical teaching system was designed by using multimedia interaction technology of converting pictures into animation and incorporating them into videos. Besides, teaching effect of the system was analyzed based on findings of an experiment and a questionnaire. As shown in the analysis result, the multimedia interaction teaching system, which has attained a good effect in practical teaching for the animation major, is very popular among students. In addition, the system enhances students' learning interest and efficiency through an intelligent way, helps students get rid of the space-time restriction and reinforce their capacity of independent learning. Generally, this paper aims to improve the effect of practice teaching for the animation major.
\end{abstract}

Index Terms - multimedia interaction, animation, practical teaching, multimedia teaching

\section{INTRODUCTION}

As an independent form of integrated art, animation has become one of the important fields in the creative cultural industry energetically emphasized by all countries. Different from animated firm in the general sense, animation is an expressive form of integrated art incorporating painting, cartoon, film, digital media, photography, music, literature and many other types of art [1]. With the continuous social progress and ceaseless increase in the need of talents, China has gradually paid more attention to and invested more in education, achieving significant improvement in animation education. However, while affirming such achievements, we should also admit that there are still problems in China's animation education, especially the severe problem of low-level market applicability among students due to their lack of practice [2]. Therefore, it is extremely urgent to enhance practical ability of students majoring in animation. In this situation, application of multimedia interaction in practical courses of animation can play a key role in solving this problem. Multimedia interaction technology [3] is applied to realize more vivid and specific communication between human and computer through integrating and processing multimedia information such as texts, pictures, videos and audio data by a computer.

Ghanizadeh and Razavi [4] used multimedia interaction technology in oral language teaching. Their study focused on the utilization of this corpus for training or learning about the limitations and needs of an interactive spoken dialogue interface for human-machine communication. Berk [5] led his team to use multimedia technology in the course of human anatomy, finding the role of multimedia interaction technology in enhancing students' enthusiasm, of reusable objects repository in meeting students' education needs of health science program, and of interactive multimedia instruction in effectively clarifying relevant concepts and mechanisms for the students. Thamarasseri [6] pointed out in his research that the brain processes information using two channels - visual and auditory. The brain can accommodate more new information when information is presented via both channels. By making full use of technology-based tools and this multimodal processing capability, we can dramatically enhance students' learning through multimedia instruction.

With the increasing attention from China to its animation education, many Chinese experts and scholars have done sufficient researches on the mode of practical teaching for animation. Zhang et al. [7] took practical teaching of animation in Beijing Union University for example and proposed to provide students with practice opportunities through the close industry-university-research cooperation based on university resources and social resources, so as to enhance their practical level in animation production. Some researchers established a multimedia network resource library, introduced the content and detailed steps of construction of the teaching resource library for animation, and then experimentally concluded that the system has some positive effects on teaching [8]. To facilitate Taijiquan course teaching and students' independent study, Zhang [9] discussed the making of animation videos for Taijiquan teaching in combination with the currently popular three-dimensional animation technology, helped students to master the essentials of all movements in Taijiquan in a more independent and visual way and, meanwhile, greatly enriched the teaching forms of Taijiquan .

However, when making a multimedia video courseware, a producer may lose some videos, or fail to find related video resources or encounter some difficulties such as the low intelligence level of data retrieval. In consideration of the above-mentioned shortcomings, this research put forward a new video stitching technology which can convert pictures into a video or a micro-video in a relatively concise and fast manner and is helpful for the fabrication of multimedia video courseware.

This research is featured by the following innovations: (1) The technology proposed in this research has none of the following shortcomings of hardware teaching networks such as huge investment, difficulty in installation and maintenance, ghosting and water ripples in image transmission and restricted line transmission distance; (2) It has overcome shortcomings of other similar software teaching networks such as low broadcasting efficiency, long voice delay, complicated operation, as well as poor stability and compatibility. 


\section{Specification ApPliCATION OF VideO Editing TECHNOLOGY AND MULTIMEDIA INTERACTION TECHNOLOGY IN ANIMATION PRACTICAL TEACHING}

This paper plans to combine a specific multimedia interaction technology which transforms pictures into animation and stitches it with video clips into a microvideo with practical teaching of animation to build the multimedia interaction teaching system and to describe the effect of multimedia interaction technology in enhancing practical ability in animation production.

After going through a strict software and hardware test procedure, the multimedia software system in this research is proved to be able to comprehensively support operating systems of the Windows series including Windows 9X, Windows Me, Windows NT 4.0, Windows 2000, Windows XP and Windows PXE diskless workstation. It is a teaching system characterized by high usability, high compatibility and high stability, supports cross-selection campus network teaching, shows good performance in its various network cards, sound cards and graphics cards, and expresses no sign of instability.

\section{A. AnimationTechnical content}

The response principle of the technology system is shown in Figure 1.

Figure 1 clearly and concisely expresses the response principle of the system. Accordingly, the system sends original data and a data processing request from the user terminal; then, video synthesis materials are formed after processing by the server; later, the video producing module engages in standardized video processing and stitching of corresponding materials to form a themed micro-video, which is then returned to the user through the server. The user terminal of the system can be either a computer or a smart mobile device, making it convenient and fast for people to practically convert pictures into animation and to produce micro-videos.

Specific steps of the method are shown in Figure 2. At first, the user uploads pictures and video materials, and simultaneously sends a request for material retrieval to the server. Picture materials include the pictures to be processed and corresponding background pictures; video materials contain one or more materials to be stitched. Secondly, the server stores the materials retrieved and data uploaded by the user as video synthesis materials into cache and then shunts such materials according to their different formats. Picture materials enter the picture processing unit, are converted to animation by means of motion processing and then are processed into a standardized animation video document. Meanwhile, after video materials are processed by the video processing unit, a standard video document will be generated. Finally, the standardized animation video document and the video document are stitched to form a complete micro-video with background music after loading and using background music; then, the micro-video is returned to the user.

As shown in Figure 3, producing pictures into animation is the most critical step of the method. Ordinary pictures should be changed in terms of their size and edge, and processed into animation video clips which rotate continuously and ceaselessly bring quick results through the animation effect algorithm, namely, image morphology processing and location superposition processing. After undergoing zooming processing, background pictures can

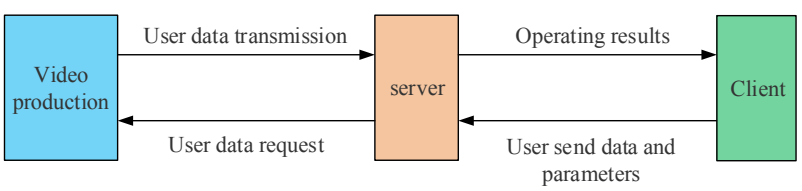

Figure 1. Response principle of the multimedia interaction technology system

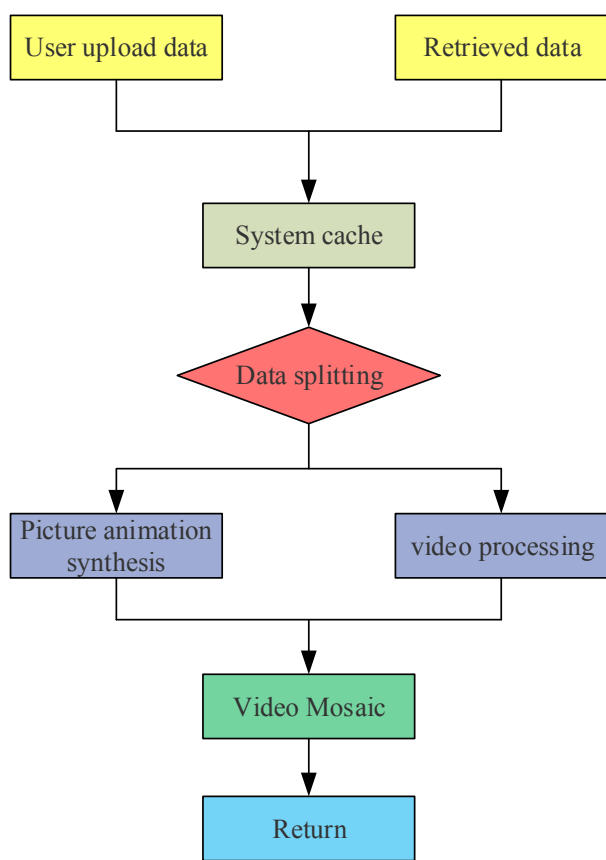

Figure 2. Flow chart of using multimedia interaction technology

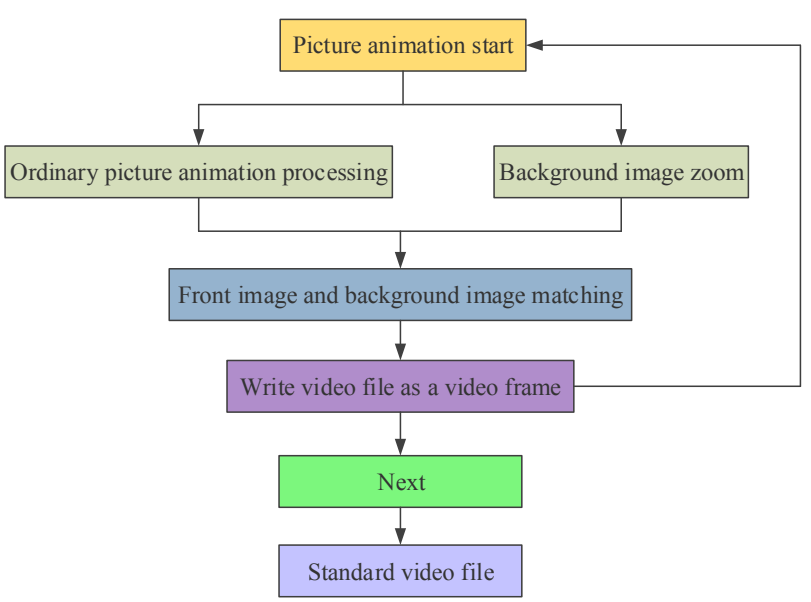

Figure 3. Flow chart of picture animation production through multimedia interaction technologyInterface of multimedia interaction teaching system

become standard ones. Ordinary pictures and background pictures are matched and overlaid to form a standard animation video document. The method can add the animation effect in pictures in a simple and fast way and can help one to easily finish the production of a teaching micro-video for enhancing the intuitive sense of teaching.

Through the homepage of the system demonstrated in Figure 4, we can see that: (1) the class model set in this system can be dragged and altered at will and be saved automatically in different classroom conditions. (2) With an extremely high broadcast efficiency, the screen can still show good performance even if the network condition is 


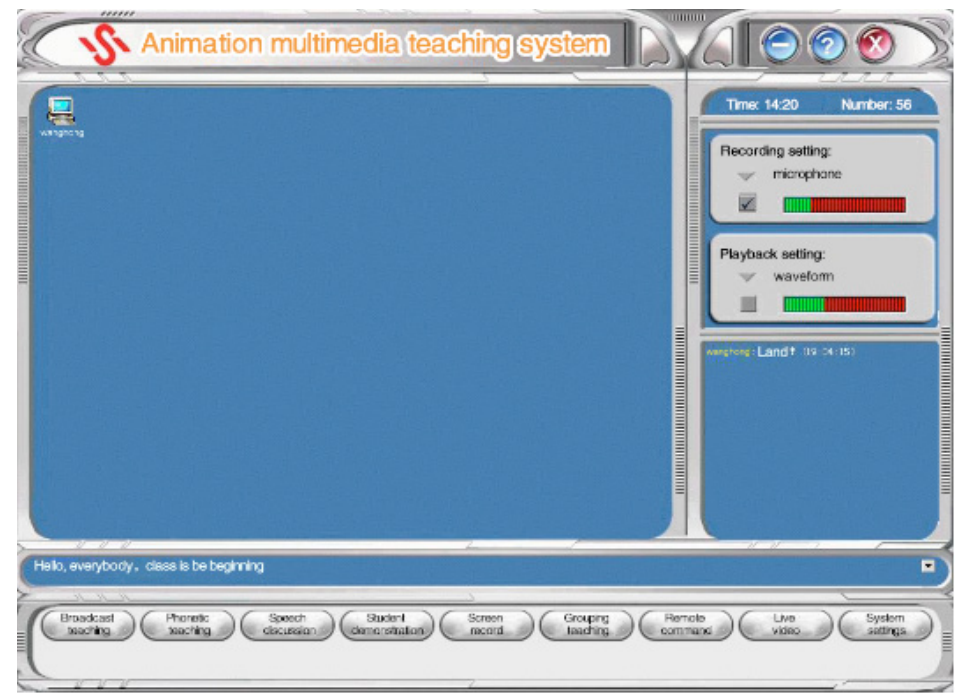

Figure 4. Homepage of the multimedia interaction technology system

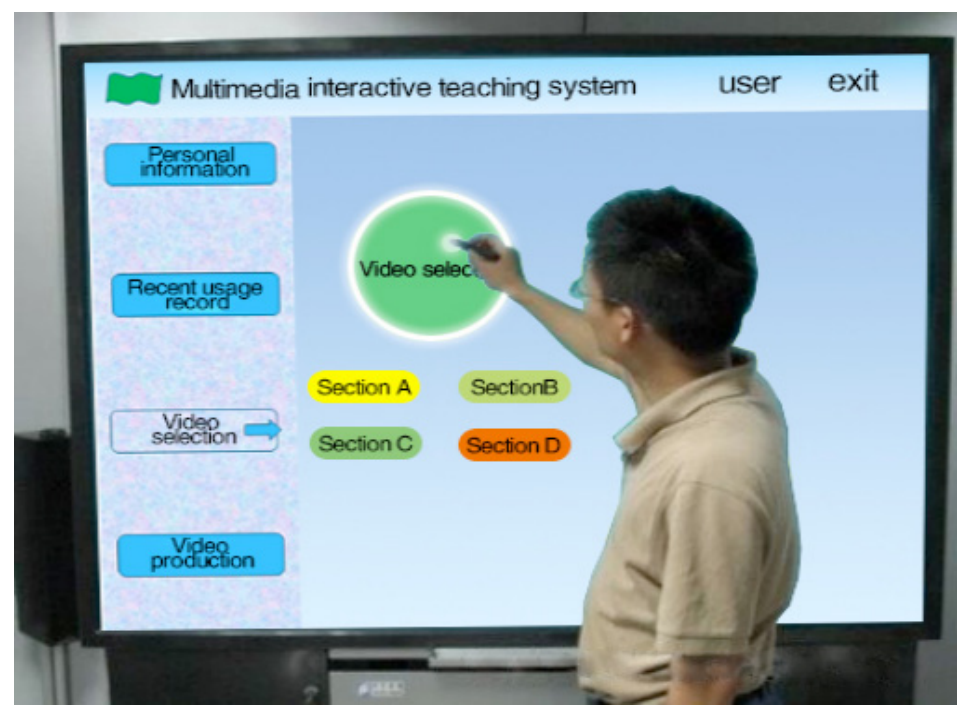

Figure 5. Operation Interface of the Multimedia Interaction Technology System

poor; besides, it can broadcast course-related multimedia courseware. (3) The sound of English broadcast and VCD broadcast is distinct and noise-free. (4) Students are allowed to speak when the teacher is giving broadcast teaching and phonetic teaching, and it is convenient to change speaking students. Meanwhile a group of students are allowed to join in or quit the teaching rank. The whole software design skillfully combines students' demonstration and monitoring broadcast, making the interaction between the teacher and students more natural and flexible; during remote control, the teacher can cooperatively work with the remotely controlled students. (5) The integrated use of screen recording and electronic ferule can achieve E-lesson preparation. (6) The function of voice discussion can divide the whole class into the same group or several groups for in-class discussion, without interference with each other. (7) The function of homework submission can be manipulated easily by the teacher to collect students' homework. (8) The function of electronic roll call brings convenience for the teacher to make a statistical record about students' attendance.

From the clear and concise operation interface of this multimedia interaction teaching system, it can be observed that the operating system provides such functions as personal information query, retrieval of recently watched videos, retrieval of all videos, practical video producing, etc. Through the operation interface, it is possible for students to view their individual student number, learning records and other learning information, retrieve recently watched videos and contribute to their quick query and review; by using the function of video selection, students can retrieve and watch all the video courseware uploaded by the teacher; the interaction technology system also provides the function of independent video producing; after the user uploads picture materials, original video materials and audio materials, the system will automatically generate a certain themed micro video. It can be found from system operation interface that the system's functions are not strong and need further improvement.

In general, the system interface is concise and practical and its essential operation points can be mastered without complex trainings, exactly fitting teaching practices. However, this system completes courseware production only through converting pictures into videos; thus, the interaction means and system function are too simplex and need to be further researched and improved. 


\section{CASE StUdy}

\section{B. Objects of experiment}

A total number of 112 students majoring in animation in University of Science and Technology Liaoning from 2015 in Liaoning province of China, including 53 male students and 59 female students, were selected and divided according to their student numbers into 2 groups, namely: the experimental group and the control group; each group consisted of 56 students. The experiment involved practical teaching which lasted two weeks; the two groups of students were compared in aspects of their ages, academic scores, etc. The differences have no statistical significance and are comparable.

\section{Methods}

The control group adopted the traditional PPT teaching mode. Specifically, the professional teacher taught the practical curriculum for animation by following the PPT teaching mode within one semester. This curriculum was taught on Monday, Wednesday and Friday every week, with 2 hours each time.

The experimental group adopted the above-mentioned multimedia interaction video producing system for teaching; this curriculum was also taught on Monday, Wednesday and Friday of each week within one semester, with 2 hours each time.

\section{Content of examination}

After two weeks of teaching, the two groups of students were organized to take corresponding animation theory and practical operation examinations. After the examinations, the method of questionnaire was taken on students of the experimental group, to learn their practical experience of being taught in this system.

\section{E. Statistical method}

Statistical analysis the two groups of students' scores in the theory and practical operation examination was executed with the SPSS 15.0 statistical software. The t test method was used to compare and analyze data of the two groups. $\mathrm{P}<0.05$, showing that the difference has statistical significance.

\section{F. Results}

Figure 6 presents analysis on scores of the experimental group and the control group in the animation theory and practical operation examination.

It can be seen from figure 6 that scores of the experimental group in both the animation theory examination and practical operation examination are obviously higher than those of the control group, which indicates that the multimedia interaction teaching mode has enhanced students' interest in learning animation, improved the teaching effect and obviously raised the level of practical animation teaching.

After the examinations, the 56 students of the experimental group were required to fill the questionnaire about the effect and defects of the multimedia interaction teaching system. A total number of 56 questionnaires were issued, all of which were valid and recovered; the recovery rate of valid questionnaires is $100 \%$. Evaluations of the experimental group on the teaching system are shown in Figure 7.

It can be learned from figure 7 that students of the experimental group taught in the multimedia interaction system highly evaluated the effect of this system. More than $90 \%$ of those students thought that with the multimedia interaction system can improve their interest and efficiency in learning the practical animation curriculum. More than $98 \%$ of students from the experimental group believed that the system can enhance their own interest and efficiency in learning.

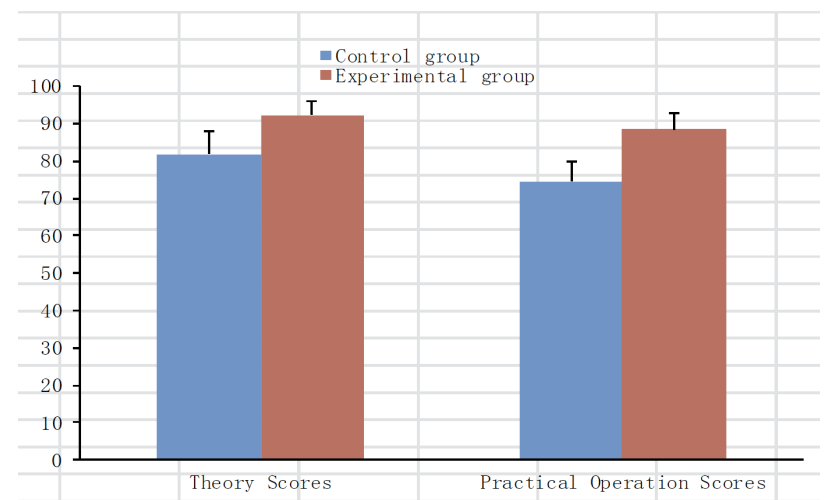

Figure 6. Comparison between the Experimental Group and the Control Group in Scores of Theory and Practical Operation Examination

\section{agree $\square$ Basically Agree $\square$ Disagree}

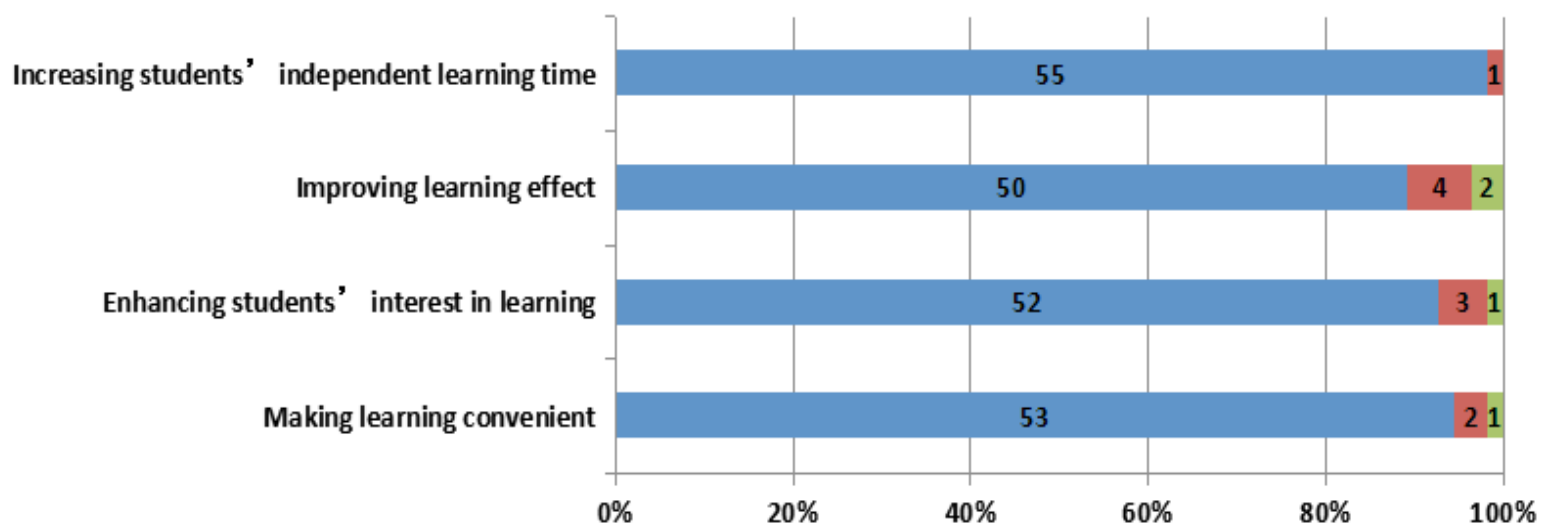

Figure 7. Evaluations of the experimental group on the multimedia interaction teaching system (example) 


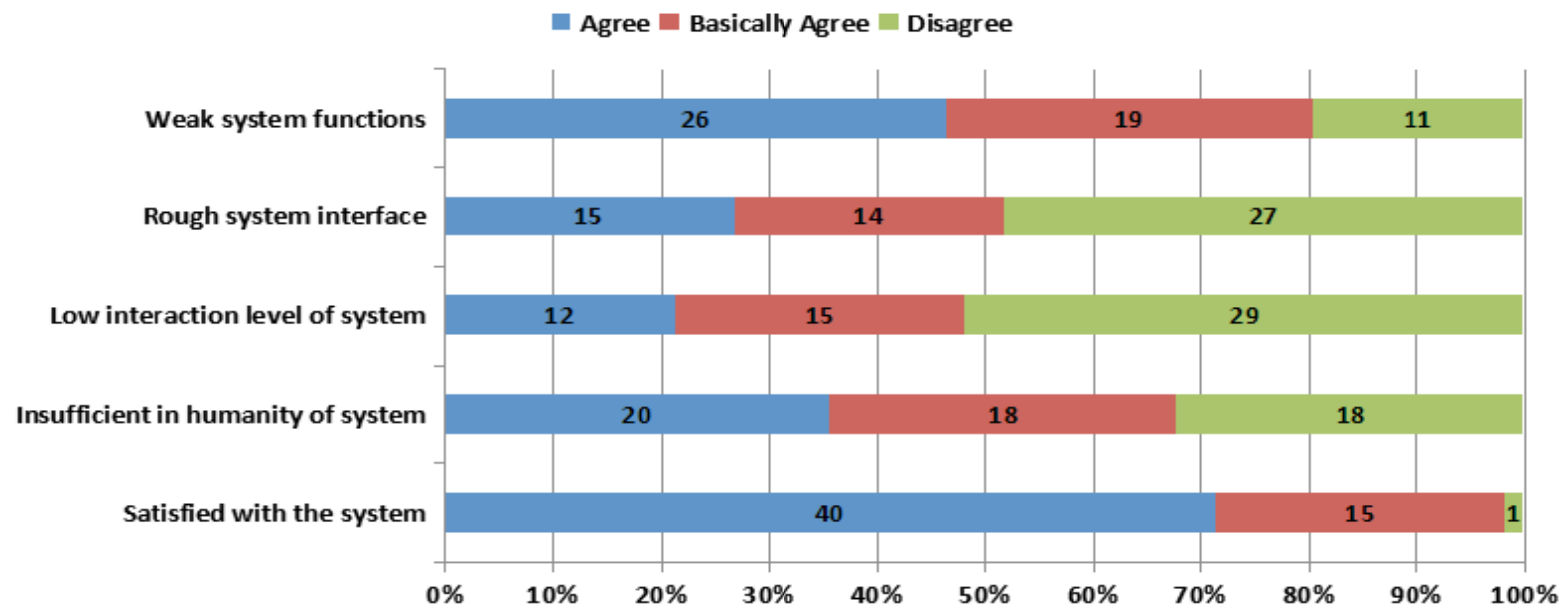

Figure 8. Statistical results of the system's defects (example)

Besides collecting students' idea on the system effect, the questionnaire also investigated the defects and shortcomings existing in the system, with of the purpose of improving the system performance and making it more adaptive to teaching needs. Statistical results of survey on the system's defects are given in figure 8 .

From figure 8 , we can see that students in the experimental group were satisfied with the system and suggested improving the system's functions, humanized setting and interface while affirming achievements of the system design.

\section{CONCLUSION}

This paper used the integrated multimedia interaction technology of changing pictures into animation and stitching it with video clips in the practical teaching system for animation. Through the system, teachers can make video courseware, while students can independently choose courseware to learn and practice making video courseware by using the practical application version.

This paper tested effect of using the system through a questionnaire and examinations. The result shows that the system is effective in the following aspects: (1) the mode of multimedia interaction teaching strengthens students' interest in learning animation, enhances the teaching effect and significantly promotes the level of practical animation teaching. (2) Application of the multimedia interaction system in animation practice course learning helps students get rid of learning at fixed times and places, allows students to learn anytime and anywhere to increase their time in independent learning, and makes learning more convenient. On the whole, application of multimedia interaction technology in practice course learning for animation can better connect modern science and technology with students' learning, imperceptibly change their learning habits and thus enhance their learning interest and efficiency. However, there are still shortcomings in this system: (1) the system's functions are too simplex. Only the application of merely multimedia interaction technology in the teaching system can only enhance the effect of teaching in a limited way. (2) With a low interactive level, the system only consists of interactive means such as video watching and video production.
In this sense, it is required to enhance interactive level of the system so as to achieve humanization and practicability of the system.

\section{REFERENCES}

[1] Luo G.Q., "The Four Views about Animation Major Construction in Private Higher Vocational College," Computer Programming Skills \& Maintenance, vol. 19, no. 10, pp. 152-153, May 2012.

[2] Liang Y.Q., "Establishment and Implementation of Practical Teaching System for Animation Specialty," Computer Education, vol. 9, no. 18, pp. 88-92, September 2011.

[3] Robbins R.N., Mellins C.A., Leu C.S., et al., "Enhancing Lay Counselor Capacity to Improve Patient Outcomes with Multimedia Technology," Aids \& Behavior, vol. 19, no. 2, pp. 1-14, June 2015. http://dx.doi.org/10.1007/s10461-014-0988-4

[4] Ghanizadeh A., Razavi A., "The impact of using multimedia in English high school classes on students' language achievement and goal orientation," International Journal of Research Studies in Educational Technology, vol. 4, no. 2, pp. 31-42, October 2015. http://dx.doi.org/10.5861/ijrset.2015.1183

[5] Berk R.A., "Multimedia Teaching with Video Clips: TV, Movies, YouTube, and mtvU in the College Classroom," International Journal of Technology in Teaching \& Learning, vol. 5, no. 1, pp. 1-21, January 2009.

[6] Thamarasseri I., "Edification of Multimedia Resources: Aligning Technology for Student Empowerment," i-Manager's Journal of Educational Technology, vol. 11, no. 3, pp. 9-15, OctoberDecember 2014.

[7] Zhang L.G., Bo F.L., Wang L.L., "Construction and Thought on Mode of Animation Practical Teaching," Information Technology Classroom, no. 12, pp. 97-99, December 2008.

[8] Kong S.R., "Applied undergraduate professional animation teaching resources storehouse construction,” Journal of Nanchang College of Education, no. 4, pp. 51-52, April 2013.

[9] Zhang L., Liu H.L., Cai A.Q., "Discussion on animation production for 24-style Shadowboxing teaching based on Maya Technology," Wuxian hulian keji, vol. 4, no. 7, pp. 238-240, July 2013.

\section{AUTHORS}

Yufeng Shen is a lecturer in University of Science and Technology Liaoning, Anshan, 114051 China. His research interests include multimedia teaching and Animation. (asshenyufeng@163.com)

Submitted 07 August 2016. Published as resubmitted by the author 16 September 2016. 